\title{
ILCEA
}

Revue de l'Institut des langues et cultures

d'Europe, Amérique, Afrique, Asie et Australie

14 | 2011

Traduction et Ergonomie

\section{Technical and Instrumental Competence in the Translator's Workplace: Using Process Research to Identify Educational and Ergonomic Needs}

Compétence technique et instrumentale du traducteur : une recherche sur les processus au travail pour identifier les besoins pédagogiques et ergonomiques

\section{Gary Massey and Maureen Ehrensberger-Dow}

\section{OpenEdition}

\section{Journals}

Electronic version

URL: http://journals.openedition.org/ilcea/1060

DOI: 10.4000/ilcea.1060

ISSN: 2101-0609

\section{Publisher}

UGA Éditions/Université Grenoble Alpes

Printed version

ISBN: 978-2-84310-203-5

ISSN: $1639-6073$

\section{Electronic reference}

Gary Massey and Maureen Ehrensberger-Dow, «Technical and Instrumental Competence in the Translator's Workplace: Using Process Research to Identify Educational and Ergonomic Needs", ILCEA [Online], 14 | 2011, Online since 30 June 2011, connection on 01 May 2019. URL : http:// journals.openedition.org/ilcea/1060; DOI : 10.4000/ilcea.1060

This text was automatically generated on 1 May 2019.

(C) ILCEA 


\section{Technical and Instrumental Competence in the Translator's Workplace: Using Process Research to Identify Educational and Ergonomic Needs}

Compétence technique et instrumentale du traducteur : une recherche sur les processus au travail pour identifier les besoins pédagogiques et ergonomiques

\section{Gary Massey and Maureen Ehrensberger-Dow}

1 Translator trainers and the translation profession have for some time considered the acquisition and deployment of technical and instrumental competence, defined by the $\mathrm{PACTE}^{1}$ research group as "predominantly procedural knowledge related to the use of documentation resources and information, and communication technologies applied to translation" (PACTE, 2009, p. 208), to be important components of general translation competence. The European Master's in Translation (EMT expert group, 2009, pp. 3 ff.), for example, establishes a reference framework for the competences applied to the language professions. Among other things, this stresses the importance of thematic competence, "knowing how to search for appropriate information to gain a better grasp of the thematic aspects of a document" (EMT expert group, 2009, p. 7), and of information mining competence, which includes identifying information and documentation requirements, developing strategies for research, extracting and processing task-relevant information, developing evaluation criteria, using tools and search engines effectively and archiving information (EMT expert group, 2009, p. 6). It also places emphasis on technological competence, notably integrating software to help in translation, correction and research, adapting existing tools and becoming familiar with new ones, producing translations in various formats for different media and, finally, knowing the possibilities and limitations of machine translation (EMT expert group, 2009, p. 7). In the world of professional practice, the European standard Translation services-service requirements 
specifies research competence, information acquisition and processing as well as technical competence (EN 15038, 2006, p. 7) as necessary prerequisites for professional translators. As Gouadec (2007, p. 93) observes, "efficient translation [...] requires the translator to be proficient in all the communication techniques involved. This means mastering a complex set of tools, techniques and media [...]".

2 The teachers' and practitioners' view is echoed in translation theory, where technical and instrumental competence occupy key positions in various models of translation competence. The PACTE group (2005, pp. 615 f.) draws a distinction between internal and external support in the decision-making processes of translators. While internal support involves the retrieval of knowledge from the translators' long-term memory (Prassl, 2010, p.57), external support refers to the consultation of external resources such as dictionaries, encyclopædias and terminology databases. The skills and knowledge associated with such consultations is referred to by PACTE as the instrumental subcompetence; of the six sub-competences posited in their model, the instrumental subcompetence is one of the three key components specific to translation competence (PACTE, 2005, p. 611). Initial results of research conducted by PACTE to test their model support their contention that the instrumental sub-competence is characteristic of translation expertise, significantly distinguishing professional translators from nonprofessionals (PACTE, 2005, pp. $615 \mathrm{ff}$.; PACTE, 2009, pp. $227 \mathrm{f}$.). Corresponding to the PACTE group's "instrumental sub-competence", the "tools and research competence" described in Göpferich's translation competence model comprises "the ability to use translation-specific conventional and electronic tools" (Göpferich, 2009, p.21). In common with PACTE, Göpferich $(2009$, p. 13) considers this to be one of the three subcompetences that play a decisive role in translation competence.

The relative weight given to technical and instrumental competence by practitioners, trainers and scholars has been accompanied by a growing interest among the cognitive translation research community. After all, it is only possible to make translators "masters of communications technologies" (Gouadec, 2007, p. 93) if they can be trained effectively, which is itself predicated on knowledge of technical and information practices and problems during the actual process of translation. Earlier empirical studies on information behaviour among translation students (e.g. Atkins \& Varantola, 1998; Livbjerg \& Mees, 2003; Mackintosh, 1998; Varantola, 1998) and professionals (e.g. Fulford, 2001; Nord, 2002, 2009) concentrated largely on dictionary or terminology resource use alone. Recently, however, researchers have begun to investigate the ways in which novice and professional translators use the far wider range of linguistic and extra-linguistic resources now at their disposal in order to determine how technical and instrumental competence develop and may be fostered (e.g. Alves \& Campos, 2009; EhrensbergerDow \& Massey, 2008; O’Brien, 2006; PACTE, 2005, 2009; Pinto \& Sales, 2008; Prassl, 2010). As White et al. (2008, p. 577) rightly point out, "with the growing global need for translation, [...] the time is opportune to study information needs and behaviors of professional translators". Clearly, there is a strong ergonomic dimension to the investigation of technical and information behaviour, which inevitably involves how translators interact with the various tools and resources available to them in their working environments.

4 This paper reports on some ergonomically relevant findings from a study currently taking place at our institute about translators' technical and information behaviour. Forming part of a larger-scale Capturing Translation Processes research project ${ }^{2}$, Translation 
Tools in the Workplace explores the impact of tools and external resources on translation processes. A principal objective of this sub-project is to ascertain how much technical and instrumental competence translators in Switzerland possess, with a view to identifying problem areas and user needs in order to enhance the workplace practices of students and professionals.

Explorative data analysis suggests that a number of such problems and needs are ergonomic in nature, with technological aids appearing to interfere with the cognitive process of translation by both slowing it down and diminishing the quality of the product. We indicate how research of this kind can help identify potential ergonomic problems inherent in the design of user interfaces and feed into targeted instruction in technical and instrumental competence (cf. Massey et al., 2008) that meets the ergonomic needs of student and professional translators.

\section{Investigating workplace processes: research design and methods}

6 Translation Tools in the Workplace comprises three main phases. The first phase examines the self-reported resource use and information behaviour of professional translators. It consists of two parallel surveys, one targeted at freelance translators belonging to professional translation associations in Switzerland, the other at staff translators. ${ }^{3}$ The second phase of the sub-project adopts the multi-method approach reported on in detail by Ehrensberger-Dow \& Massey (2008) and Ehrensberger-Dow \& Perrin (2009). It combines data from ethnographic observation of the translation situation, surveys and semi-structured interviews to determine self-reported practices, keystroke logging, computer screenshot recordings, cue-based retrospective verbalisations of recorded translation processes and eye-tracking. The data obtained permit us to observe tool use and research practices in the workplace and gain insight into the cognitive processes involved in these aspects of translation. The target groups and versions of interest are students at three points in their translation careers (beginners, advanced students, recent graduates), professionals with different levels of experience, various language combinations (German-English/English-German, German-French/French-German, German-Italian/Italian-German), and translation into the first/dominant language or second/foreign language.

7 The third phase of Translation Tools in the Workplace centres on knowledge transfer. Through a process of evaluation and generalisation, the behaviour reported, observed and described in phases 1 and 2 of the sub-project will be analysed so as to optimise the training of students and professionals.

\section{Workplace practices and ergonomic needs}

8 The freelance survey which initiated the sub-project's first phase was completed by 110 professional translators, all of whom are members of the two leading professional translation associations in Switzerland. ${ }^{4}$ The demographics of the sample can be summarised as follows: $82 \%$ of the participants were aged between 30 and $59,79 \%$ had a formal education in translation, $68 \%$ had more than 10 years' experience as translators and $80 \%$ translated more than 20 standard pages per month. 
Respondents were asked to recall a representative recent translation or revision assignment and to provide information on tool and resource types together with the manner and order in which these were used. The assignments covered a wide range of text genres and domains of non-literary translation. 98\% involved German as either a source or target language, $45 \%$ French, 31\% English and $21 \%$ Italian, a distribution that is representative of the Swiss translation market. Just over half of the assignments (51\%) were carried out with the aid of Translation Memory tools.

In answer to questions about how often they use various types of external resources when confronted with linguistic and extra-linguistic problems during a translation task, participants indicated frequencies on a five-point Likert scale: very often, often, occasionally, seldom, never. The results show clearly that most freelancers, irrespective of their language versions, use search engines, online multilingual dictionaries and terminology databanks often or very often. In addition, a majority of them also consult online parallel texts and encyclopædias often or very often to solve extra-linguistic problems.

11 The survey results are generally replicated by the data gathered and analysed during the second phase of the project. Here, too, the external resources typically used by both student and professional translators are search engines, online dictionaries, terminology databases, online parallel texts and online encyclopædias. None of the participants in the second phase employed Translation Memory systems during the translation processes that were recorded. ${ }^{5}$ Since all of the translations discussed in this paper were done using Microsoft Word, this word-processing program and its tools can be added to the list of the most frequently used resources identified in the computer-monitoring phase of Translation Tools in the Workplace.

In the following, examples of technical and information behaviour drawn from the second phase of the project are presented. Although making no particular claim to representativeness, they do reflect problem types repeatedly observed in our data. They therefore serve to illustrate how process-oriented research into workplace practices can help identify ergonomic needs in the use of common external resources and thus support a research-driven, evidence-based approach to translator training.

The examples below have been selected to show how ergonomic issues can adversely affect both the speed and efficiency of the translation process and, ultimately, the success of the translation product. They are drawn from the processes of beginner (student), novice (recent graduate) and experienced professional translators working on timed German-English or English-German translations of short journalistic texts. In each case, ergonomically-related problems are identified by a combination of overt indicators in retrospective verbal protocols (RVPs) and of disturbances in translation and informationretrieval processes, unsuccessful search strategies and inadequate translations observed in the screenshot recordings (SCR) and/or eye-tracking (ETR) data. The participants and problem indicators discussed in this paper are presented in Table 1. 
Table 1. - Overview of examples discussed in this paper.

\begin{tabular}{|c|c|c|c|c|c|}
\hline Participant & $\begin{array}{l}\text { Level of translation training/ } \\
\text { experience }\end{array}$ & $\begin{array}{l}\text { Age } \\
\text { group }\end{array}$ & $\begin{array}{l}\text { First } \\
\text { language }\end{array}$ & $\begin{array}{l}\text { Translation } \\
\text { direction }\end{array}$ & $\begin{array}{l}\text { Problem indicator } \\
\text { source }\end{array}$ \\
\hline Pro09 & $\begin{array}{l}\text { Professional translator with postgraduate } \\
\text { translation \& interpreting training }\end{array}$ & $40-50$ & English & $\begin{array}{l}\text { German- } \\
\text { English }\end{array}$ & RVP, SCR \\
\hline Nov0405 & $\begin{array}{l}\text { Graduate translation \& interpreting } \\
\text { student with } \mathrm{B} \Lambda \text { in translation }\end{array}$ & $20-25$ & German & $\begin{array}{l}\text { German- } \\
\text { English }\end{array}$ & SCR, ETR \\
\hline Beg0901 & $\begin{array}{l}\text { First-year undergraduate on BA } \\
\text { translation programme }\end{array}$ & $20-25$ & German & $\begin{array}{l}\text { German- } \\
\text { English }\end{array}$ & RVP, SCR, ETR \\
\hline Beg0904 & $\begin{array}{l}\text { First-year undergraduate on BA } \\
\text { translation programme }\end{array}$ & $20-25$ & German & $\begin{array}{l}\text { English- } \\
\text { German }\end{array}$ & RVP, SCR, ETR \\
\hline Beg0911 & $\begin{array}{l}\text { First-year undergraduate on } \mathrm{B} \Lambda \\
\text { translation programme }\end{array}$ & $20-25$ & German & $\begin{array}{l}\text { German- } \\
\text { English }\end{array}$ & SCR, ETR \\
\hline Beg0941 & $\begin{array}{l}\text { First-year undergraduate on } \mathrm{B} \Lambda \\
\text { translation programme }\end{array}$ & $18-20$ & German & $\begin{array}{l}\text { German- } \\
\text { English }\end{array}$ & RVP, SCR, ETR \\
\hline
\end{tabular}

14 The first example is taken from a data set with the processes of seven professionals (working outside their customary environment) and seven student translators translating the same source text, which is discussed in detail by Massey \& Ehrensberger-Dow (2010, pp. 135 ff.). The professional Pro09 consults external resources in order to translate the source-text term "EU-Schnellwarnsystem RAPEX" (the EU-approved English translation is "rapid alert system RAPEX"). The consultation takes 11 seconds, the fastest of the consultations performed by the professionals and the second fastest in the whole set. However, the resultant translation is unsuccessful, as Pro09 indicates in his retrospective verbal protocol when he says "So 'rapid warning system' instead of 'rapid alert system', which would be considered a very, very bad mistake, back where I work. <laughs>".

Throughout the process of translation, the screenshot recording shows Pro09 overwriting the German source text in the Microsoft Word file with the English target text. For this particular consultation, Pro09 uses the taskbar in Windows XP to switch from the translation document to a single, full-screen search engine window, enters the search term "EU rapex", consults the search-engine results page, switches back to the translation document in a single, full-screen window and enters the incorrect targetlanguage term from memory. As Pro09 states in his retrospective verbalisation, the translation is a combination of his original intuition of what the solution could be (internal support) and external resource consultation (external support). Although the correct solution is quickly found and identified, ergonomic aspects of the consultation and transfer process appear to interfere with its success. Switching between single windows and overwriting the source text may have overloaded Pro09's short-term memory. The mistake could undoubtedly have been avoided through simple techniques such as copy-pasting the solution found directly into the target text or keeping multiple windows open at the same time.

Multiple window management can present an ergonomic problem in its own right. Despite belonging to a supposedly computer literate cohort of younger students, Beg0901 is seen to have considerable difficulty keeping more than one window open on the desktop at the same time and switching between open files. As a result, the translation process slows down substantially, with Beg0901 taking an undue amount of time to locate the source-text and target-text passages she requires. Retrospectively commenting on the eye-tracking data, she says:

It bothered me a bit ... I didn't really know how I should do it ... I usually have a printed version [of the source text] next to me. Switching back and forth [between files] bothered me a bit. ${ }^{6}$ (Beg0901) 

data indicates window management to be an issue for many beginners. The graduate Nov0405 shows how it should be done, streamlining the drafting process by arranging her source-text window above her target-text window and constantly scanning both.

As already mentioned, all the translations recorded in phase 2 of our project have so far been performed using Microsoft Word. The translation process of Beg0911 is manifestly blocked by inadequate knowledge and handling of this program's proofing tools. At the point in her target text when she translates the source-text term "Strandungen" as "strandings", Beg0911 is distracted by the wavy green underline which appears under this word. The eye-tracker shows two long fixations, after which she opens a pop-up menu to see what Microsoft Word offers as a correction. The menu suggests two alternatives, "stranding" at the top, followed by "standings". She inserts the second alternative from the menu and the underline disappears. She then corrects "standings" back to "strandings", and the wavy green underline reappears. Beg0911 continues with the rest of the translation and never returns to correct "strandings", despite the insecurity she feels and acknowledges in her retrospective verbalisation:

The next sentence went quite well at the beginning ... oh no <laughs> ... I had something in mind and first wrote it like that and then thought no, I have to start it differently so that the sentence can ... that so, so I could end it properly ... here uh it showed that it was wrong, then I wanted to change it, but it was still wrong so I just left it. I don't know if it is still wrong. (Beg0911)

The recorded actions of Beg0911 strongly suggest two weaknesses. In the first place, she appears to be unfamiliar with the proofing conventions in Word, the green underline indicating a grammatical error due to the incorrect plural form. As a result of the confusion this causes, Beg0911 fails to identify the problem at hand and therefore overlooks "stranding" as a possible solution (and, incidentally, a perfectly acceptable translation). In this case, inadequate technical competence turns a potentially helpful ergonomic tool into a hindrance. Secondly, she adopts a recursive revision pattern during the drafting phase, allowing the perceived problem to interrupt the translation process while never reaching an acceptable solution. Procedurally, a more efficient and effective approach could be to separate the translation process into clearly segmented orientation, drafting and revision phases (cf. Jakobsen, 2002).

Different ergonomic issues are apparent in the processes of Beg0904, Beg0941 and Nov0405, all of whom encounter various difficulties with the interfaces of search engines, online encyclopædias or online dictionaries. Confronted with the problem of translating the English acronym "MoD" (for the UK "Ministry of Defence") into German in a text about the stranding of whales caused by military experiments with sonar equipment, Beg0904 opens the Swiss version of the Google search engine ${ }^{7}$ and enters the query "MoD" in the basic search bar. The first three hits on the results page are, in the following order, "Mod (Subkultur) - Wikipedia", "Mod - Wikipedia" and "Ministry of Defence-home" (see Figure 1). 
Figure 1. - Detail of the Google results page for the query “Mod" by Beg0904.

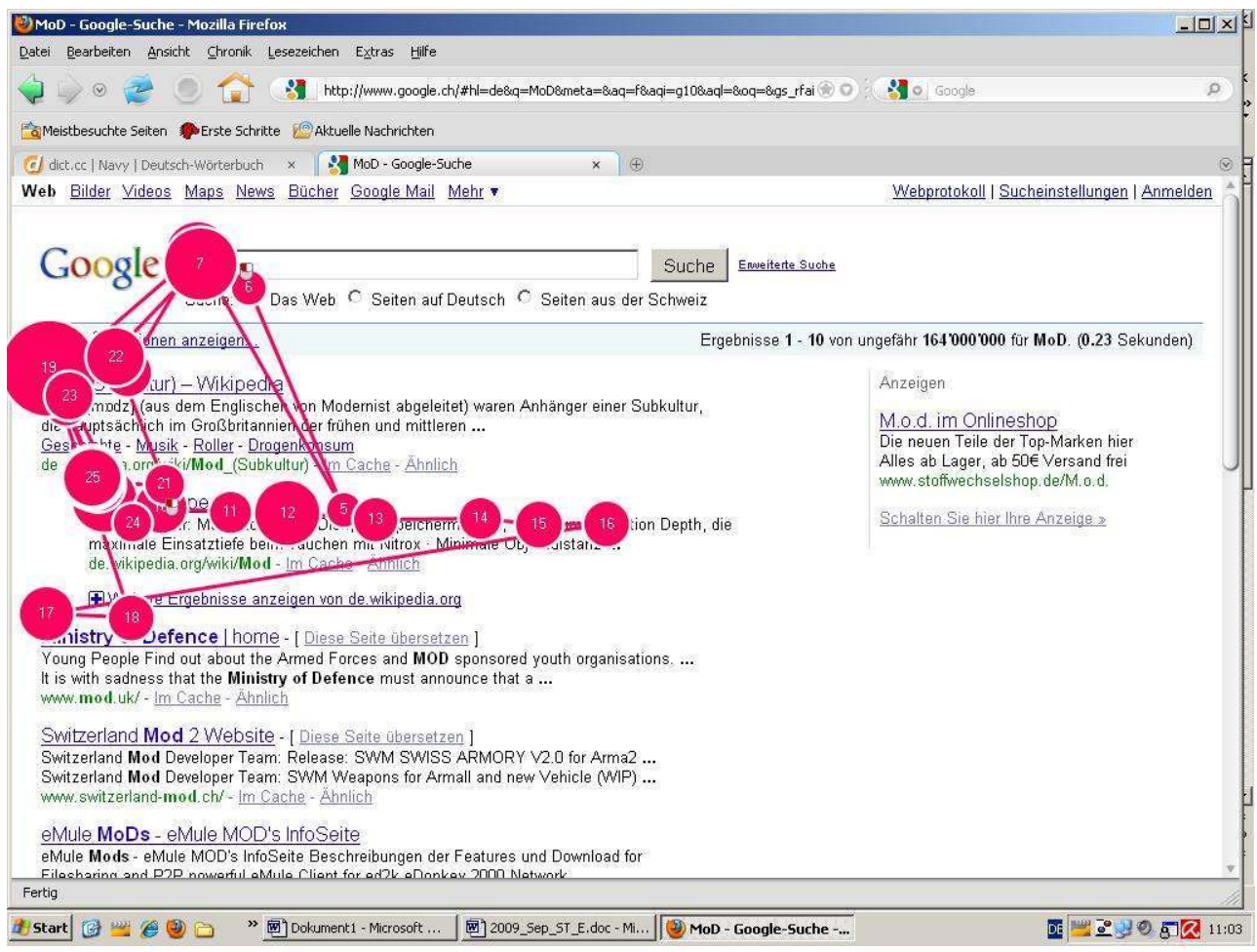

The dots indicate gaze fixations recorded by the eye-tracking software. The larger the dot, the longer the duration of the fixation. The dots are numbered to indicate the chronological order of fixations.

21 The eye-tracker shows Beg0904 concentrating her gaze largely on the first two results. Although fixations 17 and 18 are seen to rest on the third entry, she does not dwell on or explore this link. Instead, she clicks on the second, indented result with the snippet "MOD steht für Magneto Optical Disk [...]" ("MOD stands for Magneto Optical Disk [...]"), which takes her to a German-language article from the online encyclopædia Wikipedia ${ }^{8}$ summarising the various meanings of the acronym "Mod" with links to further articles. Again, the eye-tracking data show Beg0904 failing to identify a very useful reference and link, namely "Ministry of Defence" together with its official German translation, "das Verteidigungsministerium des Vereinigten Königreichs" (see Figure 2). 
Figure 2. - Detail of the German-language Wikipedia article for the query “Mod” by Beg0904.

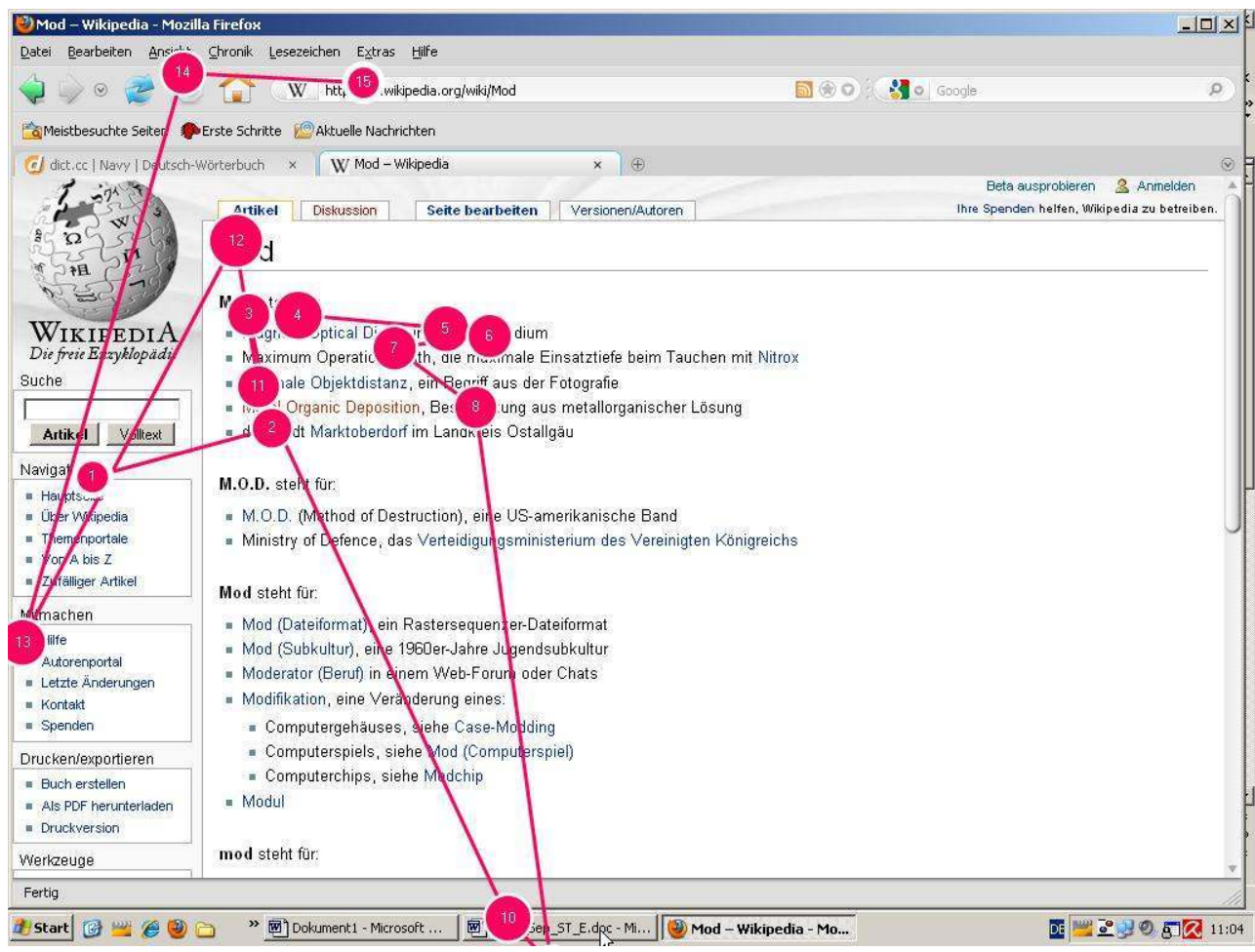

The dots indicate gaze fixations recorded by the eye-tracking software. The larger the dot, the longer the duration of the fixation. The dots are numbered to indicate the chronological order of fixations.

Simply copying and pasting the German term into her target text would have solved the problem. Instead, Beg0904 changes the URL to "http://en.wikipedia.org/wiki/Mod" in order to access the equivalent English-language article on "Mod". In third position on this page there is a reference to "Ministry of Defence" together with an explanation of the term. In the screenshot recordings, her gaze and cursor rest on this reference, but she does not click on the link (Figure 3). 
Figure 3. - Detail of the English-language Wikipedia article for the query “Mod" by Beg0904.

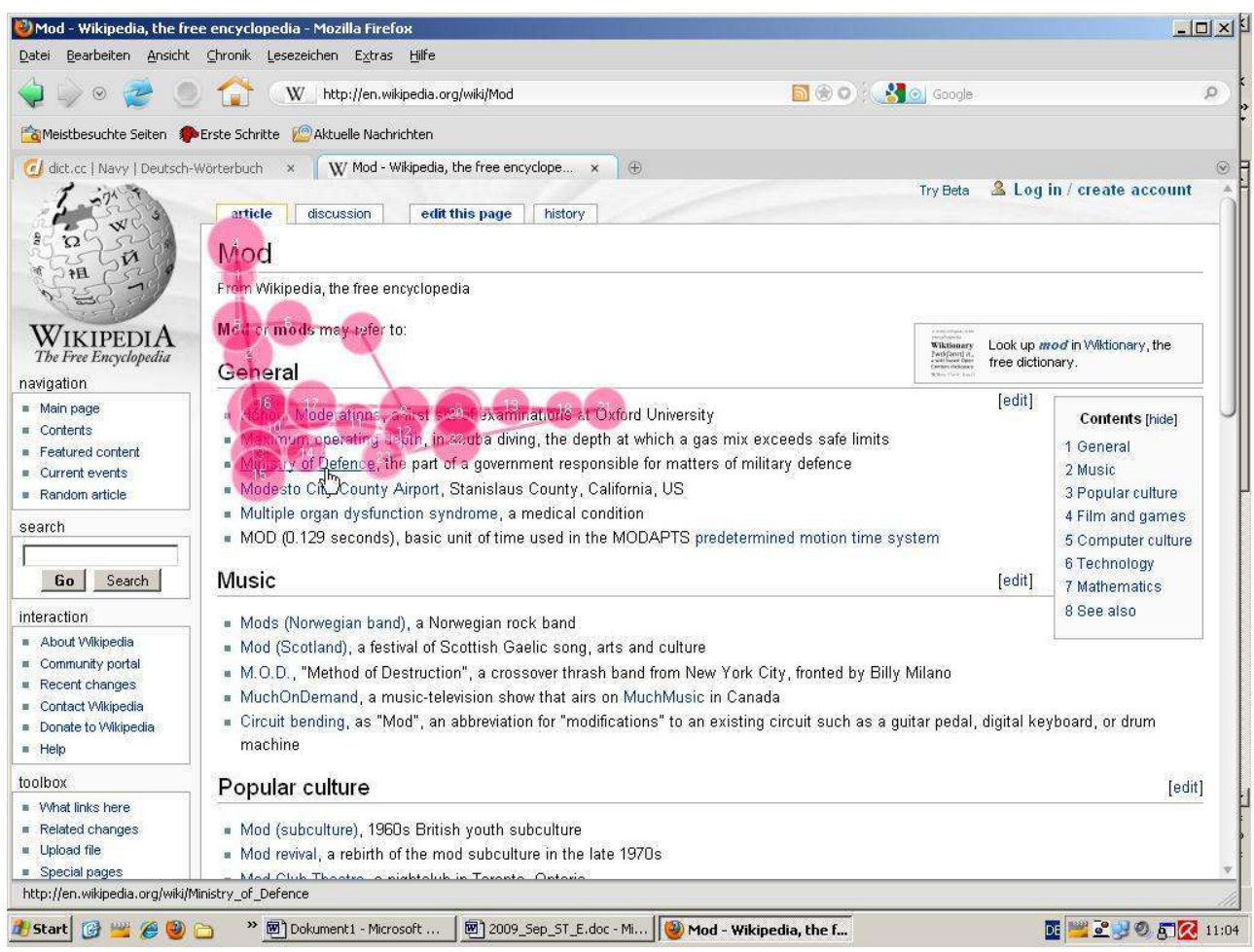

The dots indicate gaze fixations recorded by the eye-tracking software. The larger the dot, the longer the duration of the fixation. The dots are numbered to indicate the chronological order of fixations.

She writes "MoD" in her target text and continues translating. Her retrospective verbal protocol contains the following for these consultations:

Always stuck on this mod ... I had to find out what it is ... I quickly scanned it, looked to see what it ... but somehow I felt that it wouldn't give me what I was looking for. I went and looked anyway ... I noticed it was in German, but I needed English. I switched to English. Then I scanned [the page] to see if anything was there that could have something to do with it, with navy or something like that. Then I decided ... Then I had trouble getting the relative clause in, and then I decided simply to take mod over because I didn't want to waste even more time on it. Come back at the end to see if I can find it then. (Beg 0904)

Despite returning to the problem later and conducting a number of searches with various combinations of search terms, Beg0904 does not manage to find an adequate solution in her translation.

The verbalisation clearly indicates that Beg0904 is confused strategically about the ultimate goal of her consultation when she states, during what is a translation from English into German, that "I noticed it was in German, but I needed English". There is also a clear indication that she is unable to properly contextualise the information she has retrieved, which contains direct references to "defence" in English and German, when she says she was looking "to see if anything was there that could have something to do with it, with navy or something like that". However, the question is whether Beg0904's failure to see the solutions presented to her by the search engine and encyclopædia is purely cognitive in nature, or whether it is also in part related to ergonomic issues such as online reading habits and the presentation of search results. The phenomenon of "looking but not seeing" recurs repeatedly in our data at all levels of translation 
expertise. It could be argued that the undifferentiated use of the same tools and resources for varying types of linguistic and extra-linguistic problems leads to attention deficiency and unreflected search techniques. Coupled with training in problem identification, appropriate variations in resource use could provide a remedy. Even the simple expedient of using the green search engine Ecosia ${ }^{9}$ or switching to the English-language version of Google would have returned the Ministry of Defence site at the top of Beg0904's results page and, to judge by the eye-tracking data, would most certainly have caught her attention.

In the case of online dictionary interfaces, too, the consultation process can be helped or hindered by fundamental aspects of manipulation and usability. To find a solution for "Strandung", Beg0941 looks for the online dictionary service Reverso ${ }^{10}$ by typing "reverso" in the Swiss version of Google's basic search bar. On the results page, she selects the fourth entry in the list. This opens the Reverso bilingual dictionary search interface, into which she types "Strandung", failing to notice that the pre-selected dictionary is for the Spanish-English language pair. Beg0941 requires a full 33 seconds to recognise and correct the error, her eye movements clearly demonstrating that the arrangement of language pairs and translation directions in the "Choose a dictionary" section of the web page do not facilitate her search for the dictionary she needed. A related usability problem occurs when Nov0405 consults the dict.cc ${ }^{11}$ German-English online dictionary service for the English translation of the German verb "begünstigen" ("to favour/ facilitate"). Because the dictionary always lists the English search results on the left of the page and the German on the right, irrespective of translation directionality, Nov0405 is forced to read from right to left, which appears to hold up her decision-making process as her eyes repeatedly move back and forth between the English and German lists. As well as having implications for training in resource evaluation, selection and manipulation, the insights furnished by such data as these could also help service providers improve the ergonomics of their interface design.

\section{Conclusion}

27 In summing up the above findings, we can broadly classify the ergonomic needs suggested by our data according to problem type: inefficient resource and desktop management, deficient knowledge of (automated) tool features and ineffective interaction with user interfaces. Potential solutions lie in optimising the efficiency and effectiveness of translators' technical and information behaviour through heightened problem awareness, through increased familiarity with resource features and capabilities, and through adequate evaluation, selection and manipulation of resources. Finally, by using process research to discover more about language professionals' technical and information behaviour, providers themselves may enhance the usability of their tools and resources.

Although technical and instrumental competence can be considered key aspects of translation competence, the technical and information behaviour of translators has only recently emerged as a significant area of research in Translation Studies. The multimethod approach of the Translation Tools in the Workplace sub-project has provided interesting preliminary findings on ergonomically relevant problems among translation students and professionals. It is anticipated that, as we discover more about translators' technical and information behaviour at various levels of experience and competence, in 
diverse settings and in different language combinations, we will be able to offer dedicated training to meet ergonomic needs across a range of target groups.

\section{BIBLIOGRAPHY}

\section{Sources cited:}

Alves Fabio and CAMPos Tânia Liparini, "Translation technology in time: investigating the impact of translation memory systems and time pressure on types of internal and external support", in S. Göpferich, A. L. Jakobsen, and I. M. Mees (eds), Behind the Mind: Methods, Models and Results in Translation Process Research (= Copenhagen Studies in Language 37), Copenhagen, Samfundslitteratur, 2009, pp. 191-218.

AtKins B. T. Sue and VARAntola Krista, "Monitoring dictionary use", in B. T. Sue Atkins (ed), Using Dictionaries: Studies of Dictionary Use by Language Learners and Translators, Tübingen, Niemeyer Verlag, 1998, pp. 83-122.

EHRENSBERGER-DOW Maureen and MASSEY Gary, "Exploring translation competence by triangulating empirical data", Norwich Papers, no. 16, 2008, pp. 1-20.

Ehrensberger-Dow Maureen and Perrin Daniel, "Capturing translation processes to access metalinguistic awareness", Across Languages and Cultures, vol. 10, no. 2, 2009, pp. 275-88.

EMT expert group, Competences for professional translators, experts in multilingual and multimedia communication, Brussels, European Commission, 2009. Available on <http://ec.europa.eu/dgs/ translation/programmes/emt/key_documents/emt_competences_translators_en.pdf> [15 January 2011].

EN 15038, Translation services - service requirements, Brussels, European Committee for Standardization, 2006.

FULFORD Heather, "Translation tools: an exploratory study of their adoption by UK freelance translators", Machine Translation, vol. 16, no. 4, 2001, pp. 219-32.

GouAdec Daniel, Translation as a Profession, Amsterdam/Philadelphia, Benjamins, 2007.

GöPFERICH Susanne, "Towards a model of translation competence and its acquisition: The longitudinal study TransComp", in S. Göpferich, A. L. Jakobsen, and I. M. Mees (eds), Behind the Mind: Methods, Models and Results in Translation Process Research (= Copenhagen Studies in Language 37), Copenhagen, Samfundslitteratur, 2009, pp. 12-37.

HANSEN Gyde, "Retrospection methods in translator training and translation research", Journal of Specialised Translation, vol. 5, 2006, pp. 2-41.

JAKOBSEN Arnt Lykke, "Translation drafting by professional translators and by translation students", in G. Hansen (ed), Empirical Translation Studies: Process and Product (= Copenhagen Studies in Language 27), Copenhagen, Samfundslitteratur, 2002, pp. 191-204.

KuјАмÄKI Pekka, "Auf der Suche nach treffenden Worten. Bildschirmvideos als Mittel zur Analyse von studentischen Übersetzungsleistungen”, in L. Kolehmainen, H. Lenk, and A. Liimatainen 
(eds), Infinite Kontrastive Hypothesen. Beiträge des Festsymposiums zum 60. Geburtstag von Irma Hyvärinen, Frankfurt am Main, Lang, 2010, pp. 141-64.

LIVBJERG Inge and MEEs Inger M., "Patterns of dictionary use in non-domain-specific translation", in F. Alves (ed), Triangulating Translation: Perspectives in Process Oriented Research, Amsterdam/ Philadelphia, John Benjamins, 2003, pp. 123-36.

MACKINTOSH Kristen, “An empirical study of dictionary use in L2-L1 translation”, in B. T. S. Atkins (ed), Using Dictionaries: Studies of Dictionary Use by Language Learners and Translators, Tübingen, Niemeyer Verlag, 1998, pp. 123-49.

MASSEY Gary and EHRENSBERGER-DOW Maureen, "Investigating demands on language professionals", Bulletin suisse de linguistique appliquée, numéro spécial, 2010, pp. 127-41. Available on <http://doc.rero.ch/record/11876?ln=fr> [1 June 2011].

MASSEY Gary, RIEDIGER Hellmut, and LENZ Simon, “Teaching instrumental competence in an elearning environment: A Swiss perspective", in R. Dimitru and K.-H. Freygang (eds), Translation Technology in Translation Classes, Iasi, Institutul European, 2008, pp. 175-83.

NORD Britta, Hilfsmittel beim Übersetzen. Eine empirische Studie zum Rechercheverhalten professioneller Übersetzer, Frankfurt am Main, Lang, 2002.

-, "In the year 1 BG (before Google): Revisiting a 1997 Study Concerning the Use of Translation Aids", in G. Wotjak (ed), Translatione via facienda. Festschrift für Christiane Nord zum 65. Geburtstag, Frankfurt am Main, Lang, 2009, pp. 203-17.

O'BRIEN Sharon, "Eye-tracking and translation memory matches", Perspectives: Studies in Translatology, vol. 14, no. 3, 2006, pp. 185-205.

PACTE, "Investigating translation competence. Conceptual and methodological issues", Meta, vol. 50, no. 2, 2005, pp. 609-19.

-, "Results of the validation of the PACTE translation competence model: acceptability and decision making", Across Languages and Cultures, vol. 10, no. 2, 2009, pp. 207-30.

PINTO Maria and SALES Dora, "Towards user-centred information literacy instruction in translation: The view of trainers", The Interpreter and Translator Trainer, vol. 2, 2008, pp. 47-74.

PRASSL Friederike, “Translators' descision-making processes in research and knowledge integration", in S. Göpferich, F. Alves, and I. M. Mees (eds), New Approaches in Translation Process Research (= Copenhagen Studies in Language 39), Copenhagen, Samfundslitteratur, 2010, pp. 5781.

PYM Anthony, "Using process studies in translator training: self-discovery through lousy experiments", in S. Göpferich, F. Alves, and I. M. Mees (eds). Methodology, Technology and Innovation in Translation Process Research (= Copenhagen Studies in Language 38), Copenhagen, Samfundslitteratur, 2009, pp. 135-56.

VARANTOLA Krista, "Translators and their use of dictionaries: User needs and user habits", in B. T. S. Atkins (ed), Using Dictionaries: Studies of Dictionary Use by Language Learners and Translators, Tübingen, Niemeyer Verlag, 1998, pp. 179-92.

White Marilyn Domas, Matteson Miriam, and Abels Eileen G., "Beyond dictionaries: Understanding information behavior of professional translators", Journal of Documentation, vol. 64, no. 4, 2008, pp. 576-601. 


\section{NOTES}

1. Process in the Acquisition of Translation Competence and Evaluation.

2. We would like to express our gratitude to the Swiss National Science Foundation for its support of this project (Grant 13DFD3_124653/1).

3. At the time of writing, the survey of freelance translators has been completed in full; we hope to report soon on the results for staff translators.

4. We would like to thank ASTTI (the Association suisse des traducteurs, terminologues et interprètes) and DÜV/AIT (the Association d'interprètes et de traducteurs) for their cooperation in allowing us to conduct this survey of their members, and Peter Jud for his help in designing the survey.

5. It is planned to record translators using Translation Memory systems at a later stage of data collection.

6. This and all subsequent retrospective verbal protocols quoted in this paper have been translated into English from German transcriptions of the original Swiss-German verbalisations.

7. <http://www.google.ch/>.

8. <http://de.wikipedia.org/wiki/Mod>.

9. $<$ http://ecosia.org/>.

10. $<$ http://dictionary.reverso.net/>.

11. $<$ http://www.dict.cc/>.

\section{ABSTRACTS}

Although technical and instrumental competence feature prominently in translation competence models and profiles, systematic cognitive research has only recently focused on how they develop, how they can be fostered, and how today's technologies, tools and information resources are impacting on the workplace processes and practices of translators. In this paper, we report on the initial phases of a process-oriented research project investigating student and professional translators' technical and information behaviour in the workplace. We indicate how research of this kind can help identify potential ergonomic problems inherent in the design of user interfaces, including those of standardised translation aids such as readily available online dictionaries. These can impede the efficiency of translation by both slowing down the translation process and diminishing the quality of the product, particularly amongst beginners. It is suggested that targeted instruction in technical and instrumental competence can counteract these effects, for example by raising translators' awareness of the potential pitfalls of indiscriminate use of technology, teaching them how to optimise their workplace practices and thus helping them to meet their ergonomic needs.

Même si, dans le domaine de la traduction, les compétences instrumentale et technique revêtent une grande importance pour les profils et les modèles de compétence, la recherche cognitive systématique a commencé depuis peu seulement à analyser la façon dont elles se développent et peuvent être encouragées et de quelle manière les technologies, les ressources documentaires et les outils influencent les pratiques des traducteurs et leurs processus de traduction sur le lieu de travail. Dans cet article, nous présentons les phases initiales d'un projet axé sur le processus qui 
examine, sur leur lieu de travail, le comportement technique et documentaire de professionnels et d'étudiants en traduction. Nous signalons dans quelle mesure une recherche de ce genre peut aider à identifier les problèmes ergonomiques potentiels inhérents au modèle de l'interface utilisateur, y compris ceux liés aux aides standardisées à la traduction, telles que les dictionnaires en ligne facilement disponibles. Ces derniers peuvent nuire à l'efficacité traductionnelle en ralentissant le processus de traduction tout en diminuant la qualité du résultat, en particulier chez les débutants. Des instructions ciblées, concernant les compétences technique et instrumentale, pourraient sans doute pallier ces effets. Ainsi, en attirant l'attention $\mathrm{du}$ traducteur sur les pièges potentiels d'une utilisation inconditionnelle de la technologie et en lui apprenant à optimiser ses pratiques de travail, pourrait-on l'aider à satisfaire ses besoins ergonomiques.

INDEX

Keywords: ergonomics, technical and instrumental competence, translation processes

Mots-clés: compétence instrumentale et technique, ergonomie, processus de traduction

\section{AUTHORS}

\section{GARY MASSEY}

Institute of Translation and Interpreting, Zurich University of Applied Sciences, Switzerland

\section{MAUREEN EHRENSBERGER-DOW}

Institute of Translation and Interpreting, Zurich University of Applied Sciences, Switzerland 